\title{
Next-generation sequencing in health-care delivery: lessons from the functional analysis of rhodopsin
}

\author{
Wayne I.L. Davies, MA, PhD ${ }^{1,2}$, Susan M. Downes, FRCOphth, MD 1,3, Josephine K. Fu, BSc', \\ Morag E. Shanks, PhD ${ }^{4}$, Richard R. Copley, BA, DPhil ${ }^{4}$, Stefano Lise, $\mathrm{PhD}^{4}$, Simon C. Ramsden, PhD ${ }^{5}$, \\ Graeme C. M. Black, FRCOphth, DPhil ${ }^{5}$, Kate Gibson, BSc ${ }^{6}$, Russell G. Foster, BSc, PhD ${ }^{1}$, \\ Mark W. Hankins, $\mathrm{PhD}^{1}$ and Andrea H. Németh, FRCP, DPhil ${ }^{1,7}$
}

Purpose: The interpretation of genetic information has always been challenging, but next-generation sequencing produces data on such a vast scale that many more variants of uncertain pathogenicity will be found. We exemplify this issue with reference to human rhodopsin, in which pathogenic mutations can lead to autosomal dominant retinitis pigmentosa.

Methods: Rhodopsin variants, with unknown pathogenicity, were found in patients by next-generation and Sanger sequencing and a multidisciplinary approach was used to determine their functional significance.

Results: Four variants in rhodopsin were identified: F45L, P53R, $\mathrm{R} 69 \mathrm{H}$, and M39R, with the latter two substitutions being novel. We investigated the cellular transport and photopigment function of all four human substitutions and found that the F45 L and $\mathrm{R} 69 \mathrm{H}$ variants

\section{INTRODUCTION}

Massively parallel high-throughput sequencing, also known as next-generation sequencing (NGS), has revolutionized our ability to analyze genomes and detect nucleotide variants. The amount of sequence information that can be generated for a particular patient under investigation is many orders of magnitude higher than conventional Sanger sequencing; within a few years, whole-genome sequencing is likely to be a reliable, rapid, and cost-effective method of mutation detection that could be applied to clinical medicine as successfully as it has been in the research laboratory. ${ }^{1}$ However, the use of these data for clinical diagnostics presents specific challenges that need to be addressed. In particular, such large-scale sequencing can lead to results that require complex analysis and if misinterpreted could ultimately lead to serious diagnostic errors. This issue was recently highlighted in a paper ${ }^{2}$ in which the authors commented that "a major challenge ... is the gap that exists between the amount of information ... needed to convincingly demonstrate a pathogenic role in a group of research subjects and the amount of information ... needed to reliably assert that a given genetic variation is responsible for a disease in an individual patient." behave like wild-type and are highly unlikely to be pathogenic. By contrast, P53R (a de novo change) and M39R were retained in the endoplasmic reticulum with significantly reduced functionality and are clearly pathogenic.

Conclusion: Potential pathogenicity of variants requires careful assessment using clinical, genetic, and functional data. We suggest that a multidisciplinary pathway of assessment, using several functional assays, will be required if next-generation sequencing is to be used effectively, reliably, and safely in the clinical environment.

Genet Med 2012:14(11):891-899

Key Words: gene; mutation; next-generation sequencing; retinitis pigmentosa; rhodopsin

In this study, we illustrate this problem with reference to rhodopsin (RH1), a key retinal protein and the primary light detector found in rod photoreceptors. Mutations in $\mathrm{RH} 1$, of which there are now over 100 identified, were among the first to be associated with human retinal disease, and different mutations in rhodopsin (e.g., P23H) were first reported over 20 years ago as a cause of autosomal dominant retinitis pigmentosa (ADRP). ${ }^{3,4}$ Retinitis pigmentosa (RP) is an inherited degeneration of the retinal photoreceptors leading to visual impairment and blindness, occuring in 1 in 3,500 people. The age of onset of ADRP is highly variable, but it is generally an adult-onset disorder and patients with ADRP usually present with a family history of the condition.

We identified four patients for whom we were unable to determine the pathogenicity of sequence variants in rhodopsin, obtaining conflicting information from bioinformatic analyses, clinical family histories, and literature searches. This prompted a further investigation into the pathogenicity of each of the variants using distinct functional assays. We conclude that two of the variants, contrary to reports in the literature, are, in fact, probably benign polymorphisms. The other two mutations, one a de novo mutation and the other

\footnotetext{
${ }^{1}$ Nuffield Department of Clinical Neuroscience, Nuffield Laboratory of Ophthalmology, John Radcliffe Hospital, University of Oxford, Oxford, UK; ${ }^{2}$ School of Animal Biology and University of Western Australia Oceans Institute, University of Western Australia, Perth, Australia; ${ }^{3}$ Oxford Eye Hospital, Oxford University Hospitals NHS Trust, Oxford, UK; ${ }^{4}$ Wellcome Trust Centre for Human Genetics, University of Oxford, Oxford, UK; ${ }^{5}$ Genetic Medicine, Manchester Academic Health Sciences Centre, Central Manchester Foundation Trust, Manchester, UK; ${ }^{6}$ Oxford Molecular Genetics Laboratory, Churchill Hospital, Oxford University Hospitals NHS Trust, Oxford, UK; ${ }^{7}$ Department of Clinical Genetics, Churchill Hospital, Oxford University Hospitals NHS Trust, Oxford, UK. Correspondence: Andrea H. Németh (andrea.nemeth@eye.ox.ac.uk) or Mark W. Hankins (mark.hankins@eye.ox.ac.uk) 
a novel mutation, are pathogenic as each substitution affected both rhodopsin trafficking and function. Our results illustrate the complexities of interpreting data in individual patients and the challenges faced when translating scientific information from the bench to the bedside. We suggest that a multidisciplinary approach, including multiple functional assays, will be required in some cases to accurately assess the pathogenicity of genetic variants in clinical practice.

\section{Clinical assessment}

\section{MATERIALS AND METHODS}

Full ophthalmic investigation was carried out (Supplementary Materials and Methods online). Consent for the study was obtained from each patient (and their relatives where appropriate) according to the Declaration of Helsinki. ${ }^{5}$ The study was approved by the Essex2 Research Ethics Committee and the Research and Development Department of the John Radcliffe Hospital, Oxford, UK.

\section{Genetic analyses}

Three of the patients were analyzed using targeted capture of 73 retinal genes followed by NGS. ${ }^{6}$ Patients 2 and 4 were screened in a pilot study of NGS in patients negative for mutations in the ATP-binding cassette, sub-family A, member 4 gene (ABCA4). Patient 3 had early-onset RP and no family history and was screened as part of a wider study on NGS in clinical diagnostics, whereas Patient 1 had a family history of ADRP and was screened in a UK National Health Service diagnostics laboratory.

Isolation of genomic DNA and Sanger sequencing were performed using standard protocols. Targeted capture was performed by hybridizing DNA libraries to NimbleGen custom $385 \mathrm{~K}$ arrays representing a total of $431 \mathrm{~kb}$ and exons of 73 genes associated with inherited retinal degeneration. DNA was sequenced on the 454 GS FLX platform (Roche, Branford, CT). ${ }^{6}$ The pathogenicity of all sequence variants was assessed using standard bioinformatic analyses (Supplementary Materials and Methods online). Multiplex ligation-dependent probe amplification (MLPA) was used to exclude the possibility of recessive disease caused by an undetected copy-number variant in the second allele and was performed using the SALSA MLPA RP kit (MRC-Holland, Amsterdam, Netherlands), according to the manufacturer's instructions (Supplementary Materials and Methods online).

\section{Bioinformatic analyses}

For NGS data, GS Mapper Software (454) was used to map sequence reads to the human reference genome. ${ }^{6}$ Variants were filtered to include nonsynonymous single-nucleotide polymorphisms (SNPs), variants within $25 \mathrm{bp}$ of the splice sites, and indels. All data were then analyzed using standard bioinformatic programs including the annotation software Alamut, and pathogenicity prediction programs PolyPhen, SIFT, and MutPred, plus literature searches and comparison with frequency data in dbSNP and the 1000 Genomes project.

\section{Construct generation}

Full-length wild-type (WT) human RH1 and variant coding regions were amplified using genomic DNA as a template in a "swift PCR for ligating in vitro constructed exons (SPLICE)" reaction ${ }^{7,8}$ and cloned into a pMT4 mammalian expression vector (Supplementary Materials and Methods online). We also included two positive controls: $\mathrm{P} 23 \mathrm{H}$, the most common pathogenic mutation in rhodopsin, ${ }^{4,9,10}$ where there is clear evidence of pathogenicity using in vitro expression systems and immunocytochemistry, ${ }^{11-15}$ and $\Delta 68-71$, which spans one of our variants and has been demonstrated to be functionally inactive..$^{16-18}$

\section{Spectrophotometry}

WT and variant constructs were transiently transfected into human embryonic kidney cells (Supplementary Materials and Methods online). Cells were harvested before isolating rhodopsin photopigments by affinity immunochromatography and binding to excess 11 -cis retinal in the dark. ${ }^{19,20}$ Dark and bleached absorbance spectra were recorded using a UV-visible spectrophotometer, and the peak sensitivity value, the lambda $\max \left(\lambda_{\max }\right)$, was determined by fitting to a standard rhodopsin template $^{21}$ as previously described ${ }^{19,20}$ (Supplementary Materials and Methods online).

\section{Trafficking analyses}

Neuronal (Neuro-2a) cells were transiently transfected with WT and mutant constructs and fixed prior to performing immunocytochemistry. Images were acquired with a LSM710 confocal microscope (Zeiss, Cambridge, UK) (Supplementary Materials and Methods online).

\section{Homology modeling}

Homology modeling of human rhodopsin (WT and mutants) was created by using Swiss-Model ${ }^{22-25}$ and DeepView/SwissPdbViewer software v.3.7 (http://www.expasy.org/spdbv/), where the human sequence was aligned to the crystal structure of bovine rhodopsin (RH1). ${ }^{26,27}$

\section{RESULTS \\ Clinical phenotypes and family histories}

These are described in Table 1, Figure 1 and Supplementary Materials and Methods online.

\section{Rhodopsin variants identified}

Four potentially pathogenic variants were discovered: the variants c.133T $>C$ (p.F45L), c.158C $>$ G (p.P53R), and c.206G >A (p.R69H) were identified by NGS in a screen of 73 genes associated with RP, and c.116T $>$ G (p.M39R) was found by Sanger sequencing. Table 2 details the results of bioinformatic prediction programs for the variants and Supplementary Figure S1 online shows the conservation of amino acids at the four positions. The bioinformatic programs gave very inconsistent results, with some predicting each variant to be benign and others to be pathogenic. 
Table 1 Summary of clinical phenotypes, mutation identification, and functional assessments

\begin{tabular}{|c|c|c|c|c|c|c|c|c|c|c|}
\hline $\begin{array}{l}\text { Patient } \\
\text { variant }\end{array}$ & Sex & $\begin{array}{c}\text { Age at } \\
\text { onset }\end{array}$ & $\begin{array}{l}\text { Age at } \\
\text { review }\end{array}$ & $\begin{array}{l}\text { Family } \\
\text { history }\end{array}$ & $\begin{array}{c}\text { Visual } \\
\text { acuities }\end{array}$ & $\begin{array}{l}\text { Clinical pheno- } \\
\text { type at review }\end{array}$ & $\begin{array}{l}\text { Functional } \\
\text { Phenotype }\end{array}$ & $\begin{array}{l}\text { Systemic } \\
\text { features }\end{array}$ & $\begin{array}{l}\text { Cellular } \\
\text { trafficking }\end{array}$ & $\begin{array}{l}\text { Photopigment } \\
\text { function }\end{array}$ \\
\hline $\begin{array}{c}\text { 1: c.116T>G } \\
\text { (p.M39R) }\end{array}$ & $\mathrm{M}$ & 27 & 49 & $\begin{array}{l}\text { Autosomal } \\
\text { dominant }\end{array}$ & $\begin{array}{l}6 / 15 \\
6 / 10\end{array}$ & Typical RP & $\begin{array}{l}\text { Constricted } \\
\text { fields, EDTs not } \\
\text { available }\end{array}$ & None & $\begin{array}{l}\text { Mostly ER } \\
\text { retention with } \\
\text { some correct } \\
\text { transportation } \\
\text { to the plasma } \\
\text { membrane }\end{array}$ & $\begin{array}{l}\text { Reduced amount } \\
\text { of viable protein } \\
\text { (19\% of WT } \\
\text { levels); spectral } \\
\text { peak similar to } \\
\text { WT }\end{array}$ \\
\hline 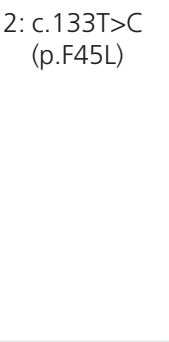 & $\mathrm{M}$ & 5 & 20 & $\begin{array}{l}\text { Simplex; } \\
\text { parents } \\
\text { had normal } \\
\text { EDTs }\end{array}$ & $\begin{array}{l}3 / 60 \\
3 / 60\end{array}$ & $\begin{array}{l}\text { Intraretinal } \\
\text { bone spicules } \\
\text { in the } \\
\text { mid-periphery; } \\
\text { yellow deposits } \\
\text { with striae at } \\
\text { maculae }\end{array}$ & $\begin{array}{l}\text { Constricted } \\
\text { visual fields; } \\
\text { EDTs consistent } \\
\text { with severe } \\
\text { rod-cone } \\
\text { dystrophy with } \\
\text { severe macular } \\
\text { involvement }\end{array}$ & $\begin{array}{l}\text { Congenital } \\
\text { myasthenic } \\
\text { syndrome } \\
\text { caused by a } \\
\text { mutation in } \\
\text { glutamine- } \\
\text { fructose-6- } \\
\text { phosphate } \\
\text { transaminase } 1 \\
\text { (GFPT1) }\end{array}$ & $\begin{array}{l}\text { Normal } \\
\text { trafficking to } \\
\text { the plasma } \\
\text { membrane }\end{array}$ & $\begin{array}{l}\text { Both the levels of } \\
\text { viable pigment } \\
\text { and spectral } \\
\text { sensitivity } \\
\text { comparable to } \\
\text { WT rhodopsin }\end{array}$ \\
\hline $\begin{array}{l}\text { 3: c. } 158 C>G \\
\text { (p.P53R) }\end{array}$ & $\mathrm{F}$ & 3 & 15 & $\begin{array}{l}\text { Simplex; } \\
\text { parents } \\
\text { normal } \\
\text { EDTs }\end{array}$ & $\begin{array}{l}6 / 12 \\
6 / 10\end{array}$ & $\begin{array}{l}\text { Typical bone } \\
\text { spicule } \\
\text { pigmentation } \\
\text { in the } \\
\text { mid-periphery } \\
\text { and central } \\
\text { edema }\end{array}$ & $\begin{array}{l}\text { Full visual fields } \\
\text { but decreased } \\
\text { central } \\
\text { sensitivity; } \\
\text { annulus of } \\
\text { increased signal } \\
\text { in maculae on } \\
\text { AF imaging; } \\
\text { EDTs consistent } \\
\text { with a cone-rod } \\
\text { dystrophy }\end{array}$ & None & $\begin{array}{l}\text { ER retention, } \\
\text { with no } \\
\text { pigment } \\
\text { found at } \\
\text { the plasma } \\
\text { membrane }\end{array}$ & $\begin{array}{l}\text { Reduced amount } \\
\text { of viable protein } \\
\text { ( } 20 \% \text { of WT } \\
\text { levels); spectral } \\
\text { peak similar to } \\
\text { WT }\end{array}$ \\
\hline $\begin{array}{c}\text { 4: c.206G >A } \\
\text { (p.R69H) }\end{array}$ & $\mathrm{F}$ & 45 & 48 & Simplex & $\begin{array}{l}6 / 12 \\
6 / 12\end{array}$ & $\begin{array}{l}\text { Pattern } \\
\text { dystrophy with } \\
\text { atrophy sparing } \\
\text { the fovea; } \\
\text { no pigment } \\
\text { deposition }\end{array}$ & $\begin{array}{l}\text { Normal fields, } \\
\text { speckled/linear } \\
\text { pattern on AF } \\
\text { imaging with } \\
\text { peripapillary } \\
\text { sparing EDTs; } \\
\text { extinguished } \\
\text { pattern ERG and } \\
\text { mildly abnormal } \\
\text { ERG }\end{array}$ & $\begin{array}{l}\text { None; } \\
\text { mitochondrial } \\
\text { mutations were } \\
\text { excluded in view } \\
\text { of phenotype }\end{array}$ & $\begin{array}{l}\text { Normal } \\
\text { trafficking to } \\
\text { the plasma } \\
\text { membrane }\end{array}$ & $\begin{array}{l}\text { Both the levels of } \\
\text { viable pigment } \\
\text { and spectral } \\
\text { sensitivity } \\
\text { comparable to } \\
\text { WT rhodopsin }\end{array}$ \\
\hline
\end{tabular}

AF, autofluorescence imaging carried out using a Heidelberg confocal scanning laser ophthalmoscope; EDT, electrodiagnostic (electrophysiology) testing; ER, endoplasmic reticulum; ERG, electroretinogram; RP, retinitis pigmentosa; WT, wild-type.

Notably, the M39R variant was considered to be benign by PolyPhen2, whereas F45L and R69H were considered likely to be pathogenic.

\section{Validation of functional analyses}

WT rhodopsin formed a fully functional photopigment with a spectral peak of absorbance $\left(\lambda_{\max }\right)$ at $496 \mathrm{~nm}$ (Figure $2 \mathbf{b}$ ), a value consistent with previous studies (e.g., $497 \mathrm{~nm}),{ }^{28}$ demonstrating the validity of our functional assessment. WT rhodopsin also showed normal trafficking to the plasma membrane of a neuronal cell line (Figure 3a). In contrast, the known mutant photopigments $\mathrm{P} 23 \mathrm{H}$ and $\Delta 68-71$ did not form functional pigments (Figure $2 \mathrm{c}, \mathbf{h}$ ) and failed to traffic to the membrane (Figure $3 \mathbf{b}, \mathbf{g}$ ), consistent with previous studies. ${ }^{4,9-15}$

\section{Integrated assessment of pathogenicity in each patient} Patient 1 (M39R) had a clear autosomal dominant family history of retinal disease, however, no other family members were available for segregation analysis. Multiplex ligation-dependent probe amplification analysis was normal (Supplementary Figure S2 online). Bioinformatic analyses were inconclusive (Table 2). On functional testing, the mutant photopigment showed impaired membrane transport with retention in the endoplasmic reticulum in addition to some normal localization at the plasma membrane (Figure $3 c)$. Spectrophotometric analyses showed that the amount of viable pigment at the membrane was about $\sim 20 \%$ of WT levels (Figure 2d and Supplementary Table S1 online) and this was able to form a light-bleachable photopigment $\left(\lambda_{\max }=497 \mathrm{~nm}\right)$ comparable with WT rhodopsin (Figure 2b). These results suggest that the predominant pathogenic mechanism of this mutation is to affect trafficking of rhodopsin to the membrane. This conclusion is supported by homology modeling showing that residue 39 is located on the outer surface and close to the point of insertion of the first transmembrane domain (TMD) (Figure 2a and Supplementary Figure S3 online), and the M39R change from a hydrophobic to a positively charged 

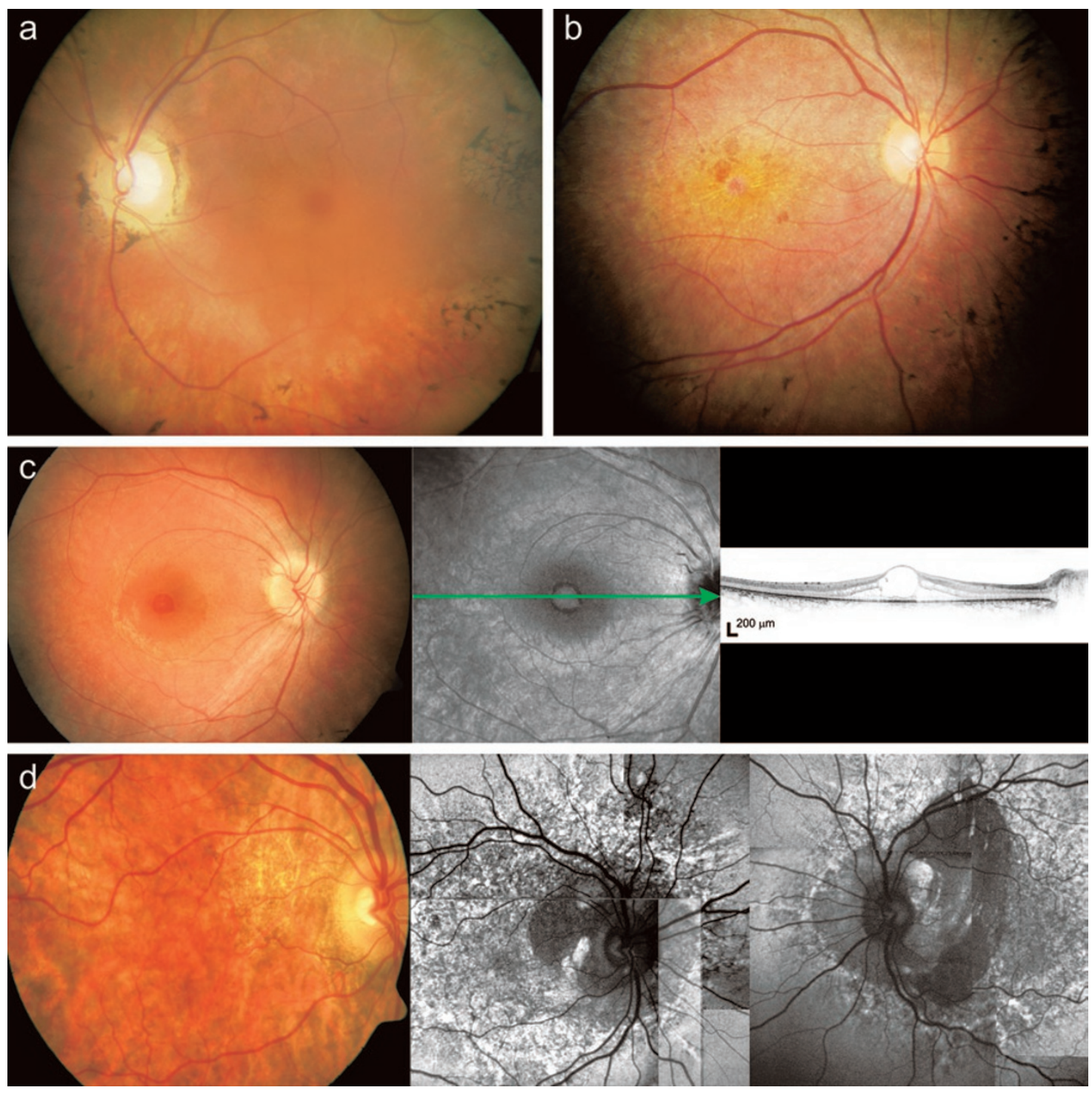

Figure 1 Ophthalmic assessment. (a) Patient 1 (M39R): color photography of the left eye showing typical features of RP. (b) Patient 2 (F45L): color image showing macular yellow deposits and features of RP. (c) Patient 3 (P53R): retinal imaging showing a cystic macula. Intraretinal pigment in midperipheral retina not shown. (d) Patient 4 (R69H): color image showing atrophic patches also seen on autofluorescence imaging with features more typical of a pattern dystrophy. RP, retinitis pigmentosa.

residue may affect the efficiency of membrane insertion. Taken together, these data suggest that the M39R mutation is likely to be the cause of ADRP in Patient 1. The presence of some functional rhodopsin may explain the adult onset of this disorder.

Patient 2 (F45L) had very early onset disease and no family history, which had initially suggested an unknown recessive disorder. Multiplex ligation-dependent probe amplification was normal, excluding a copy-number variant on the second allele as an explanation for the phenotype (Supplementary Figure S2 online). An F45L substitution has been reported to be pathogenic in ADRP patients, ${ }^{29-31}$ however, the pathogenic mechanism could not be identified. ${ }^{10}$ Bioinformatic analyses were inconclusive; the residue at site 45 is invariant across vertebrates (Supplementary Figure S1 online) and is found on the outer surface of the first TMD (Figure 2a and
Supplementary Figure S3 online), but the Grantham score predicts that the effect of the F45L substitution should be minimal (Table 2). We showed that the F45L rhodopsin pigment was transported to the plasma membrane (Figure 3d) and gave a spectral profile identical to the WT, with the level of viable protein being about $10 \%$ greater than that of a positive control (Figure 2e and Supplementary Table S1 online). We were unable to replicate a previous report that F45 Lauses endoplasmic reticulum retention and aggregate formation; ${ }^{32}$ however, in this published study, the mutation was introduced into a truncated rhodopsin cassette, which omitted both the amino- and carboxyl-termini, and cannot be accurately compared with valid experiments where a full-length protein is used. Analysis of the parents of Patient 2 showed that the F45L variant was inherited from an asymptomatic 
Table 2 Bioinformatic analyses using three commonly used mutation programs of pathogenicity, SIFT, ${ }^{37}$ PolyPhen $2,{ }^{38}$ and MutPred, ${ }^{39}$ and the Grantham score ${ }^{40}$ to determine the degree of tolerance for each amino acid substitution on the basis of physio-chemical properties

\begin{tabular}{|c|c|c|c|c|c|c|}
\hline \multirow[b]{3}{*}{ Mutation } & \multirow[b]{3}{*}{ Protein domain } & \multirow[b]{3}{*}{ Grantham score ${ }^{a}$} & \multicolumn{4}{|c|}{ Prediction program } \\
\hline & & & \multirow{2}{*}{$\begin{array}{l}\text { SIFT } \\
\text { Probability } \\
\text { score }^{b}\end{array}$} & \multirow{2}{*}{$\begin{array}{l}\text { PolyPhen2 } \\
\text { Probability } \\
\text { scorec }^{c}\end{array}$} & \multicolumn{2}{|c|}{ MutPred } \\
\hline & & & & & $\begin{array}{l}\text { Probability } \\
\text { score }^{c}\end{array}$ & $\begin{array}{l}\text { Molecular mechanism } \\
\text { disrupted ( } P \text { value) }\end{array}$ \\
\hline $\mathrm{P} 23 \mathrm{H}$ & Extracellular & 77 (Possibly not tolerated) & $\begin{array}{l}0.00 \\
\text { (Deleterious) }\end{array}$ & $\begin{array}{l}1.00 \text { (Probably } \\
\text { damaging) }\end{array}$ & 0.83 & Gain of loop $(P=0.04)$ \\
\hline M39R & Transmembrane & 91 (Possibly not tolerated) & $\begin{array}{l}0.03 \\
\text { (Deleterious) }\end{array}$ & $\begin{array}{l}0.01 \text { (Probably } \\
\text { benign) }\end{array}$ & 0.90 & $\begin{array}{l}\text { Gain of glycosylation at S38 } \\
(P=0.0862)\end{array}$ \\
\hline P53R & Transmembrane & 103 (Probably not tolerated) & $\begin{array}{l}0.00 \\
\text { (Deleterious) }\end{array}$ & $\begin{array}{l}1.00 \text { (Probably } \\
\text { damaging) }\end{array}$ & 0.71 & None \\
\hline $\mathrm{R} 69 \mathrm{H}$ & Intracellular & 69 (Possibly not tolerated) & $\begin{array}{l}0.00 \\
\text { (Deleterious) }\end{array}$ & $\begin{array}{l}1.00 \text { (Probably } \\
\text { damaging) }\end{array}$ & 0.87 & None \\
\hline
\end{tabular}

a Grantham scoring ${ }^{40}$, where $<60=$ probably tolerated; $61-99=$ possibly not tolerated; $>100=$ probably not tolerated. ${ }^{b}$ Probability of being pathogenic; $0=$ highest; $1=$ lowest. cProbability of being pathogenic: $0=$ lowest; 1 = highest.

father (Table 1 and Supplementary Table S2 online). The presence of a fully functional F45 L rhodopsin is not consistent with the very early onset and severity of ocular disease observed in Patient 2, nor would it be consistent with a reduced-penetrance allele. Collectively, our data suggest that the presence of the F45L variant is not the primary explanation for retinal disease and that the status of pathogenicity for this amino acid substitution should be reviewed.

Patient 3 (P53R) had very early onset disease, with no family history and was thought to have recessive mutations, which might be detected using targeted capture and NGS. Similar to $\mathrm{F} 45 \mathrm{~L}$, this variant was identified in a previous study ${ }^{17}$ and thought to be pathogenic; ;2,18 however, it has recently been recategorized as an "unclassified" mutation because of the lack of valid functional information..$^{10}$ Residue 53 is located in the first TMD of the rhodopsin protein structure (Figure 2a and Supplementary Figure S3 online). This amino acid is highly conserved, being present in all vertebrate rhodopsins so far studied (Supplementary Figure S1 online), and P53R is predicted to be pathogenic (Table 2). Neither parent carried the P53R change and stated parentage was confirmed using polymorphic markers (Supplementary Table S2 online). The P53R mutation, therefore, must have arisen de novo, an increasingly well-recognized phenomenon, but only the second report of such a case in rhodopsin. The first case was only recently identified. ${ }^{33}$ There were no copy-number variants in the second rhodopsin allele (Supplementary Figure S2 online). When tested using immunocytochemistry and UV-vis spectrophotometry, the P53R mutant produced viable protein at only $20 \%$ of WT levels (Figure 2f). This small amount of rhodopsin was predominantly retained in the endoplasmic reticulum (Figure $3 \mathrm{e}$ ) and failed to generate a functional photopigment (Figure 2f).
Despite both M39R and P53R producing 20\% viable protein as compared with the WT, the $\lambda_{\text {max }}$ values differed, with a peak at $489 \mathrm{~nm}$ for P53R that is short-wavelength shifted as compared with both the WT $\left(\lambda_{\max }=496 \mathrm{~nm}\right)$ (Figure 2b) and the low membrane levels of the M39R mutant $\left(\lambda_{\max }=497 \mathrm{~nm}\right)$ (Figure 2d), suggesting the P53R substitution affects not only rhodopsin membrane transport, but also 11-cis retinal chromophore handling and function, thereby providing a disease mechanism for the retinal degenerative phenotype observed in Patient 3.

Patient 4 (R69H) had late-onset disease and no family history. In vertebrates, R69 is essentially invariant across both visual and nonvisual opsins (Supplementary Figure S1 online); bioinformatic analyses predicted that this mutation would be deleterious to protein function (Table 2). Nonetheless, the $\mathrm{R} 69 \mathrm{H}$ change is located in a relatively large, open cytoplasmic pocket (Figure 2a and Supplementary Figure S3 online), so this substitution may not be expected to cause structural or functional defects in rhodopsin, especially because the amino acids in question are biochemically similar (i.e., Grantham score lies at the boundary between tolerated and not tolerated (Table 2)). However, when the human $\mathrm{R} 69 \mathrm{H}$ mutant was expressed in neuronal cells, full-length rhodopsin protein was trafficked to the membrane (Figure 3f) and produced similar levels of viable protein to those of the WT (Figure 2g and Supplementary Table S1 online). Furthermore, the R69H mutant successfully formed a lightbleachable photopigment with a $\lambda_{\text {max }}$ at $493 \mathrm{~nm}$ (Figure 2g). Although $3 \mathrm{~nm}$ short-wavelength shifted as compared with WT, the spectral peak of absorbance for the $\mathrm{R} 69 \mathrm{H}$ variant pigment lies within an acceptable experimental range $(<5 \mathrm{~nm})$. In contrast to our human data, bovine $\mathrm{R} 69 \mathrm{H}$ rhodopsin was 

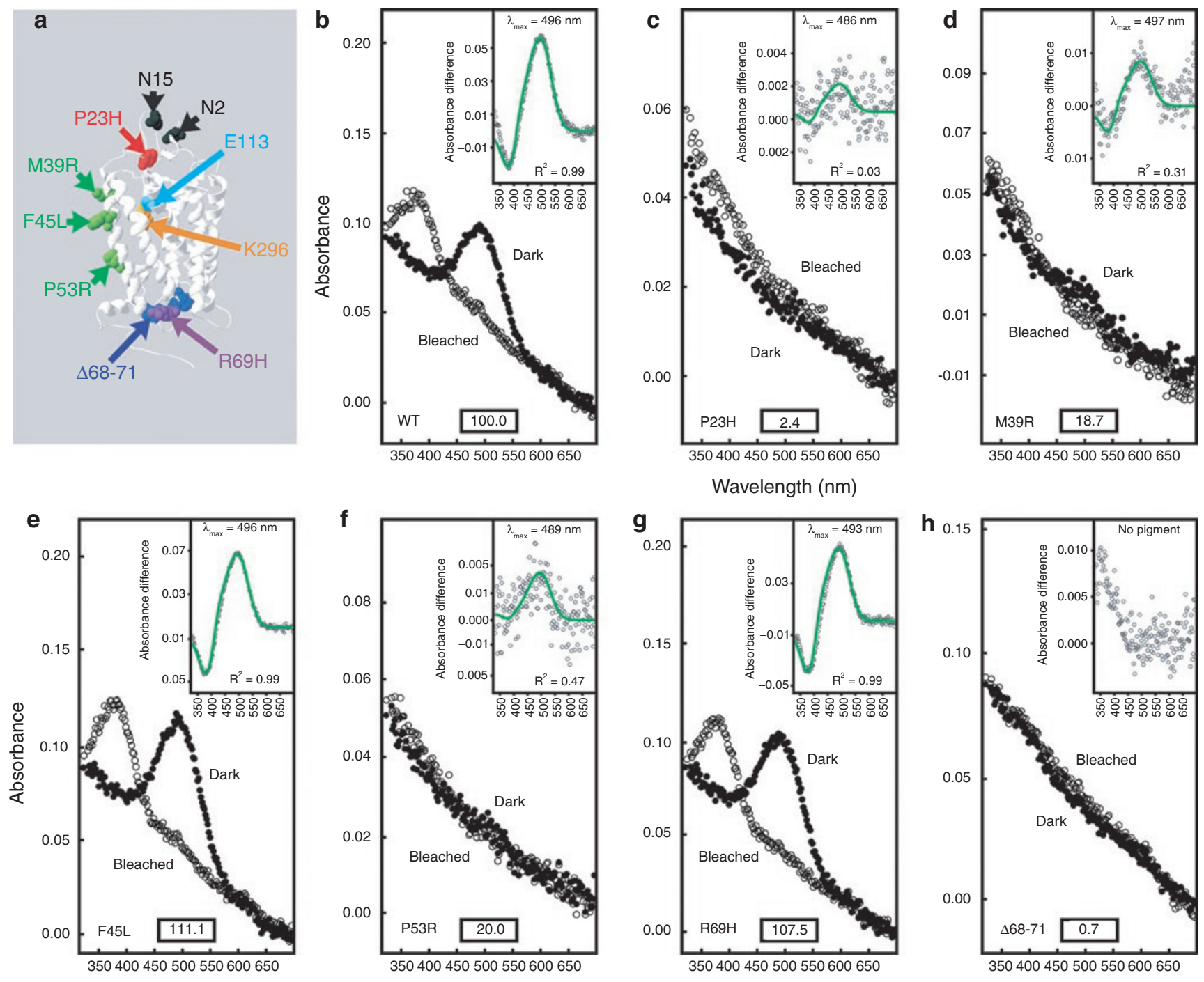

Wavelength $(\mathrm{nm})$

Figure 2 Homology modelling and absorbance spectra of wild-type and variant human rhodopsin photopigments. (a) Structural homology model of the WT human rhodopsin photopigment, modified to show the relative positions of six variants (P23H, M39R, F45L, P53R, R69H, and $\triangle 68-71$ ) in relation to the retinal chromophore attachment site at K296 (orange), the counterion at E113 (light blue), and two N-linked glycosylation sites at N2 and N15 (black). The variants are color coded on the basis of their location within the determined G protein-coupled receptor structure, where red signifies the extracellular amino-terminus, green highlights substitutions within the first transmembrane domain, and dark blue $(\Delta 68-71)$ or purple (R69H) indicates the first cytoplasmic loop. All homology models were created using Swiss Model22-25 and DeepView/Swiss-PdbViewer software v.3.7 (http://www.expasy.org/spdbv/) and are based on the crystal structure of bovine rhodopsin (RH1). ${ }^{26,27}$ (b-h) Absorbance spectra of WT and mutant human rhodopsin photopigments, reconstituted with 11-cis retinal. b, WT; c, P23H; d, M39R; e, F45L; f, P53R; g, R69H; and h, $\Delta 68-71$. For all pigments, representative dark (filled circles) and light-bleached (open circles) spectra are shown, with difference spectra (open gray circles) that have been fitted with a Govardovskii rhodopsin/vitamin- $\mathrm{A}_{1}$ template ${ }^{21}$ (green line) in the inset to determine the $\lambda_{\max }$. The percentage of viable protein (as compared with WT) is included (box close to the x-axis). WT, wild-type.

shown previously to produce an abnormally translated protein in a baculovirus expression system. ${ }^{34}$ However, we have been unable to confirm a role of $\mathrm{R} 69 \mathrm{H}$ in the pathogenicity of retinal disease in Patient 4. A c.206G >A (p.R69H) polymorphic change has been reported once in dbSNP (rs118173887; http://www.ncbi.nlm.nih.gov/projects/SNP), where the frequency of the variant allele is low $(0.008$, with a heterozygosity frequency of 0.017 ). Therefore, similar to F45L, R69H may be a rare benign polymorphism that coincidentally exists in a patient with an RP-like phenotype. If this is the case, another genetic cause for the retinal degeneration, excluding the 73 genes already screened, must be sought.

\section{DISCUSSION}

NGS was very effective in identifying rhodopsin variants in patients, but we were confronted with significant challenges when interpreting their clinical significance. This problem is not unique to NGS, but the assessment of variant pathogenicity is many orders of magnitude greater than conventional detection methodologies. 

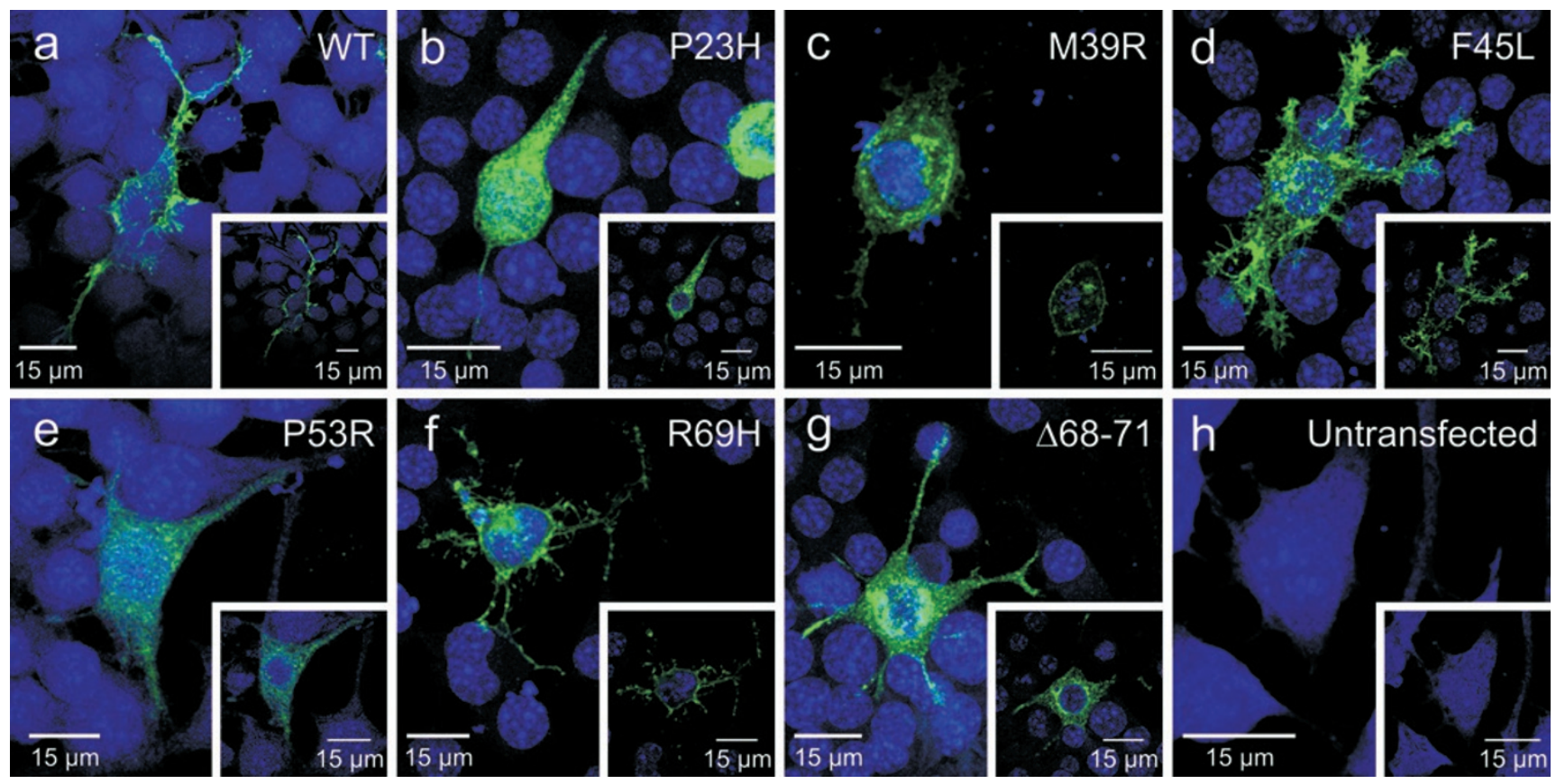

Figure 3 Immunofluorescence labeling of neural (Neuro-2a) cells transfected with WT and mutant rhodopsin photopigments with an anti-rhodopsin antibody (1D4). Panels show representative cells with no fluorescence being detected in untransfected cells. (a) WT; (b) P23H; (c) M39R; (d) F45L; (e) P53R; (f) R69H; (g) $\triangle 68-71$; (h) untransfected. The main panel indicates a Z-stack confocal image, with a central section being highlighted in the inset. WT, wild-type.

We have shown that the standard methods of assessment, such as segregation analysis, bioinformatics, and literature searches, although very useful and important, ultimately were not sufficient to make a confident molecular diagnosis. Further analysis using highly specialized functional assessment of rhodopsin was required. For example, M39R was not considered very likely to be pathogenic, on the basis of bioinformatic analyses and current knowledge of the rhodopsin structure; nonetheless, the mutation clearly demonstrated abnormal function, illustrating the value of cellular assessments. Although functional assays are not routinely available in clinical practice, these approaches, from "bedside to bench" and back again, are likely to be increasingly important as clinical medicine attempts to process and understand the enormous amount of data generated from NGS.

We also show that by integrating functional analyses into our pipeline, further insights can be gained into mechanisms of pathogenicity and mayhaveimportant therapeutic consequences in the future. ${ }^{35}$ We show that both M39R and P53R mutations significantly inhibit the trafficking of rhodopsin to the plasma membrane and the binding of the 11-cis retinal chromophore. In the P53R mutant, the effect is compounded by changes in the spectral tuning of the small level of photopigment produced. In addition, we have shown that the F45L variant traffics normally in neuronal cells and functions as a photolabile pigment similar to WT rhodopsin. It is possible that a F45L substitution could cause constitutive activity, inhibit oligomerization, reduce thermal stability, or impair the ability of rhodopsin to activate transducin (all of which we have not tested). We believe that the last possibility is unlikely as the position in the protein of the amino acid change is far removed from the experimentally determined transducin binding domains located within the second and third cytoplasmic loops ${ }^{36}$; however, this conclusion requires further confirmation. Although these potential disease mechanisms cannot be ruled out by our study, the data obtained from the functional assays conducted here, combined with the genetic analysis showing the presence of the same variant in an asymptomatic parent as the child with early-onset disease, strongly suggest that F45L does not affect any biochemical or cellular aspect of rhodopsin function. Therefore, the F45L variant is likely to be either a benign polymorphism or a genetic modifier, but it is highly unlikely to be the primary cause of disease. Clinically this is important as an alternative explanation for the retinal degeneration needs to be sought. Similarly we report a novel $\mathrm{R} 69 \mathrm{H}$ variant that was previously reported to be functionally abnormal in a baculovirus system where bovine rhodopsin was used. ${ }^{34}$ However, we found that human R69H traffics and functions normally in mammalian cells, suggesting that these inconsistencies may be, in part, because of the use of different assays or, more likely, variation between human and bovine proteins. Again, it is possible that photopigment dimerization, activation/deactivation kinetics, thermal stability, or transducin activation are impaired; however, our current data suggest that this variant functionally behaves in the same way as WT rhodopsin and further analysis would be required to exclude other possible biophysical defects.

The identification of likely benign variants challenges the broad perception of rhodopsin as an essentially immutable gene; our data suggest that there may be a greater tolerance for genetic change than initially appreciated. This view is 
supported by entries into genome databases: in addition to 42 variants entered into dbSNP, a number of rhodopsin variants of unknown pathogenicity have been reported in the exome variant server (http://evs.gs.washington.edu/EVS/). Given that rhodopsin is a well-studied protein, it was surprising that we identified two novel changes, M39R and R69H, and only the second P53R mutation. ${ }^{17}$ It was also surprising to find a de novo rhodopsin mutation, only the second to be identified and the first to be functionally assessed. This illustrates that more information is likely to be generated by further genetic and functional analyses of this gene. In conclusion, we have shown the immense power of NGS as a diagnostic tool and described the complexities of analysis. Our experience in interpreting genetic changes in such a well-known gene as rhodopsin has clearly shown that functional assessment plays a critical role in interpreting the significance of genetic variants in clinical practice. Development of appropriate analysis pipelines that can include multiple functional studies will be essential if NGS data are to provide accurate information to patients and families.

\section{SUPPLEMENTARY MATERIAL}

Supplementary material is linked to the online version of the paper at http://www.nature.com/gim

\section{ACKNOWLEDGMENTS}

We thank Navamayooran Thavanesan for his assistance in generating the full-length RH1 construct and Michelle McClements and Steven Hughes for help with the immunocytochemistry. This work was funded by the Oxford Partnership Comprehensive Biomedical Research Centre funded by the Department of Health NIHR Biomedical Research Centre Programme, awarded to A.H.N. The views expressed in this publication are those of the authors and not necessarily those of the Department of Health. W.I.L.D. was supported by a Biotechnology and Biological Sciences Research Council grant to M.W.H. We are grateful to Rosalie Crouch for the kind gift of 11-cis retinal. This study was not commissioned and only peer reviewed externally. W.I.L.D., S.M.D., J.K.F., M.E.S., K.G., and A.H.N. contributed to the generation of data; W.I.L.D., S.M.D., M.E.S., R.R.C., S.L., S.C.R., K.G., and A.H.N. performed the data analysis; G.C.M.B. and R.G.F. assisted in the study; W.I.L.D., S.M.D., M.W.H., and A.H.N. designed the experiments and prepared the manuscript.

\section{DISCLOSURE}

The authors declare no conflict of interest.

\section{REFERENCES}

1. Lupski JR, Reid JG, Gonzaga-Jauregui C, et al. Whole-genome sequencing in a patient with Charcot-Marie-Tooth neuropathy. N Engl J Med 2010;362:1181-1191.

2. Sheffield VC, Stone EM. Genomics and the eye. N Engl J Med 2011;364:1932-1942.

3. Dryja TP, McGee TL, Hahn LB, et al. Mutations within the rhodopsin gene in patients with autosomal dominant retinitis pigmentosa. N Engl J Med 1990;323:1302-1307.

4. Dryja TP, McGee TL, Reichel E, et al. A point mutation of the rhodopsin gene in one form of retinitis pigmentosa. Nature 1990;343:364-366.
5. World Medical Association declaration of Helsinki. Recommendations guiding physicians in biomedical research involving human subjects. JAMA 1997;277:925-926.

6. Shanks ME, Downes SM, Copley RR, et al. Next Generation Sequencing (NGS) as a diagnostic tool for retinal degeneration reveals a much higher detection rate in early onset disease. Eur J Hum Genet. In press.

7. Davies WL, Carvalho LS, Hunt DM. Protocol for SPLICE: a technique for generating in vitro spliced coding sequences from genomic DNA. BioTechniques Protocol Guide. New York, NY: Informa Biosciences, 2009.

8. Davies WL, Carvalho LS, Hunt DM. SPLICE: a technique for generating in vitro spliced coding sequences from genomic DNA. BioTechniques 2007:43:785-789.

9. Dryja TP, McGee TL, Hahn LB, et al. Mutations within the rhodopsin gene in patients with autosomal dominant retinitis pigmentosa. N Eng J Med 1990:323:1302-1307.

10. Mendes HF, van der Spuy J, Chapple JP, Cheetham ME. Mechanisms of cell death in rhodopsin retinitis pigmentosa: implications for therapy. Trends Mol Med 2005;11:177-185.

11. Sung CH, Schneider BG, Agarwal N, Papermaster DS, Nathans J. Functional heterogeneity of mutant rhodopsins responsible for autosomal dominant retinitis pigmentosa. Proc Natl Acad Sci USA 1991;88:8840-8844.

12. Kaushal S, Khorana HG. Structure and function in rhodopsin. 7. Point mutations associated with autosomal dominant retinitis pigmentosa. Biochemistry 1994;33:6121-6128.

13. Saliba RS, Munro PM, Luthert PJ, Cheetham ME. The cellular fate of mutant rhodopsin: quality control, degradation and aggresome formation. J Cell SCi 2002:115(Pt 14):2907-2918.

14. Frederick JM, Krasnoperova NV, Hoffmann K, et al. Mutant rhodopsin transgene expression on a null background. Invest Ophthalmol Vis Sci 2001;42:826-833.

15. Chapple JP, Cheetham ME. The chaperone environment at the cytoplasmic face of the endoplasmic reticulum can modulate rhodopsin processing and inclusion formation. J Biol Chem 2003;278:19087-19094.

16. Keen TJ, Inglehearn CF, Lester $\mathrm{DH}$, et al. Autosomal dominant retinitis pigmentosa: four new mutations in rhodopsin, one of them in the retinal attachment site. Genomics 1991;11:199-205.

17. Inglehearn CF, Keen TJ, Bashir $\mathrm{R}$, et al. A completed screen for mutations of the rhodopsin gene in a panel of patients with autosomal dominant retinitis pigmentosa. Hum Mol Genet 1992;1:41-45.

18. Sung $\mathrm{CH}$, Davenport $\mathrm{CM}$, Nathans J. Rhodopsin mutations responsible for autosomal dominant retinitis pigmentosa. Clustering of functional classes along the polypeptide chain. J Biol Chem 1993;268: 26645-26649.

19. Davies WI, Zheng L, Hughes S, et al. Functional diversity of melanopsins and their global expression in the teleost retina. Cell Mol Life Sci 2011;68: 4115-4132.

20. Davies WL, Cowing JA, Bowmaker JK, Carvalho LS, Gower DJ, Hunt DM. Shedding light on serpent sight: the visual pigments of henophidian snakes. J Neurosci 2009;29:7519-7525.

21. Govardovskii VI, Fyhrquist N, Reuter T, Kuzmin DG, Donner K. In search of the visual pigment template. Vis Neurosci 2000;17:509-528.

22. Guex N, Peitsch MC. SWISS-MODEL and the Swiss-PdbViewer: an environment for comparative protein modeling. Electrophoresis 1997;18:2714-2723.

23. Schwede T, Kopp J, Guex N, Peitsch MC. SWISS-MODEL: An automated protein homology-modeling server. Nucleic Acids Res 2003;31: 3381-3385.

24. Arnold K, Bordoli L, Kopp J, Schwede T. The SWISS-MODEL workspace: a web-based environment for protein structure homology modelling. Bioinformatics 2006;22:195-201.

25. Bordoli L, Kiefer F, Arnold K, Benkert P, Battey J, Schwede T. Protein structure homology modeling using SWISS-MODEL workspace. Nat Protoc 2009:4:1-13.

26. Palczewski K, Kumasaka T, Hori T, et al. Crystal structure of rhodopsin: A G protein-coupled receptor. Science 2000;289:739-745.

27. Okada T, Sugihara M, Bondar AN, Elstner M, Entel P, Buss V. The retinal conformation and its environment in rhodopsin in light of a new $2.2 \mathrm{~A}$ crystal structure. J Mol Bio/ 2004;342:571-583.

28. Crescitelli F, Dartnall HJ. Human visual purple. Nature 1953;172:195-197.

29. Sung $\mathrm{CH}$, Davenport $\mathrm{CM}$, Hennessey JC, et al. Rhodopsin mutations in autosomal dominant retinitis pigmentosa. Proc Natl Acad Sci USA 1991;88:6481-6485 
30. Dryja TP, McEvoy JA, McGee TL, Berson EL. Novel rhodopsin mutations Gly114Val and GIn184Pro in dominant retinitis pigmentosa. Invest Ophthalmol Vis Sci 2000;41:3124-3127.

31. Matias-Florentino M, Ayala-Ramirez R, Graue-Wiechers F, Zenteno JC. Molecular screening of rhodopsin and peripherin/RDS genes in Mexican families with autosomal dominant retinitis pigmentosa. Curr Eye Res 2009;34:1050-1056.

32. Chen YF, Wang IJ. Examining rhodopsin retention in endoplasmic reticulum and intracellular localization in vitro and in vivo by using truncated rhodopsin fragments. J Cell Biochem 2010;112: 520-530.

33. Neveling K, Collin RW, Gilissen C, et al. Next-generation genetic testing for retinitis pigmentosa. Hum Mutat 2012;33:963-972.

34. DeCaluwé GL, DeGrip WJ. Point mutations in bovine opsin can be classified in four groups with respect to their effect on the biosynthetic pathway of opsin. Biochem J 1996;320 (Pt 3):807-815.
35. Wilson JH, Wensel TG. The nature of dominant mutations of rhodopsin and implications for gene therapy. Mol Neurobio/ 2003;28:149-158.

36. Min KC, Zvyaga TA, Cypess AM, Sakmar TP. Characterization of mutant rhodopsins responsible for autosomal dominant retinitis pigmentosa. Mutations on the cytoplasmic surface affect transducin activation. J Biol Chem 1993;268:9400-9404.

37. Kumar P, Henikoff S, Ng PC. Predicting the effects of coding nonsynonymous variants on protein function using the SIFT algorithm. Nat Protoc 2009;4:1073-1081.

38. Adzhubei IA, Schmidt S, Peshkin L, et al. A method and server for predicting damaging missense mutations. Nat Methods 2010;7:248-249.

39. Li B, Krishnan VG, Mort ME, et al. Automated inference of molecular mechanisms of disease from amino acid substitutions. Bioinformatics 2009;25:2744-2750.

40. Grantham R. Amino acid difference formula to help explain protein evolution. Science 1974;185:862-864. 